\title{
Consumer Responses to Explicit Sexual Stimuli in Advertising: Artistic vs Provocative Style
}

\author{
Marcello Tedeschi ${ }^{1}$, Beatrice Luceri ${ }^{2}$, Sabrina Latusi ${ }^{2}$, Donata Tania Vergura ${ }^{2} \&$ Cristina Zerbini $^{2}$ \\ ${ }^{1}$ Department of Communication and Economics, University of Modena and Reggio Emilia, Reggio Emilia, Italy \\ ${ }^{2}$ Department of Economics and Management, University of Parma, Parma, Italy \\ Correspondence: Donata Tania Vergura, Department of Economics and Management, University of Parma, \\ Parma, Italy.
}

Received: September 11, 2017

Accepted: November 23, 2017 Online Published: December 19, 2017

doi:10.5539/ibr.v11n1p102

URL: https://doi.org/10.5539/ibr.v11n1p102

\begin{abstract}
This study extends prior research on sexual appeal advertising by developing a model of consumer responses to explicit sexual stimuli conveyed through different expressive styles (artistic versus provocative). A between-subjects experimental design $(\mathrm{N}=369)$ was conducted. The theoretical model includes ad-, brand- and behaviour-related variables. Structural equation modelling was used to estimate the hypothesized relationships.

Findings reveal that the use of an artistic format stimulates a better response than the use of images in merely provocative poses. From a female consumer perspective, all paths were positive and significant when exposed to the artistic nudity stimuli, with the only exception of the positive emotions-purchase intention relationship. Results suggest a moderating role of the mode of representing sexual images on attitude-intention relationships. From a male consumer perspective, the response was similar, but any effect was present between attitude towards the advertisement and purchase intention. Support was found for a moderating influence of expressive styles on positive emotion-attitude towards the brand relationship.
\end{abstract}

The paper sheds new lights on the way explicit sexual stimuli can be represented, offering a contribution to improving the communication effectiveness of products and brands that exploit sexual stimuli.

Keywords: expressive styles, gender, print advertising, sexual stimuli, structural equation modelling

\section{Introduction}

Since ancient times, humans have used images of female and male bodies to communicate to each other. From the caves of Lascaux in southern France to those of the Tibesti Massif in Chad or those of Addaura, Sicily, stylized figures of men and animals were used to represent strength or courage, foster religious rites or to symbolize membership in a clan. Over time, the use of pictures depicting naked bodies of women or men has become an art form. These images were already present in the Mesopotamian culture, and they are brought to us through the images of goddess Astarte, protectress of sexuality, or Aphrodite for the ancient Greeks or Venus for the Romans. At that time, it was not unusual at all or outrageous to picture in statues or paintings the naked or partially naked bodies of deities. Nudity and sex have always been an important part of cultural models. They have defined from time to time different meanings: strength, power, and aggression have often been associated with the figure of the man, while fertility, seduction or shame have often been associated with the female image.

Currently, images related with sex appeal, sexuality or double senses have broadly crossed the original artistic expression. They have become part both of our day-to-day experience and of our cultural and stylistic model through a slow but unrelenting process of the sexualisation of products and services. Often, and explicitly, creative advertising strategies have combined images with sexual content to new, or already existing products, to stimulate attention, interest and emotions of consumers to induce them to the purchase. Advertising has been, since its beginning, sexually allusive and it has always adopted images related to nudity.

In early 1870, the Pearl Tobacco Company publicized its products with a poster in which was depicted a naked woman on tiptoes touching the waves on the background of a light cloud of smoke. In the same period, the Duke $\&$ Son inserted in their packages some cards representing different themes. Among them were a series of actresses that were more or less undressed. This product enrichment was justified by the need to stiffen the package of cigarettes, together with the aim of increasing customer loyalty. The cards caused, in fact, an active 
exchange between collectors and some, particularly 'daring' cards, were certainly more appreciated than others. This mode of expression was not coupled solely to cigarettes or tobacco.-Stanley and Helen Resor (owners of the agency J. Walter Thompson), in 1917, made an intentional use of sex to sell Woodburry's products using the image of a completely naked woman.

Since then, the number of brands that have made explicit use of sexual content with naked or half-naked bodies is extremely high. Kalvin Klein, Tom Ford and Victoria's Secret are just some of the brands that have supported such images with increasingly explicit sexual innuendo in jeans, underwear and fragrances. There are, in this endless list, also brands and product categories that do not have much affinity with bodies and sex. It is easy to recall the long series of advertisement of Budweiser beer among alcoholic drinks or the allusive advertisements by Burger King and Arby's in the fast food sector.

All the examples cited highlight that both art and advertising have used nudity and sex to represent opposite concepts as sacred, secular, pagan, or hedonistic, ascetic. These contents could be also an expression of our own frailty or of our desire to be provocative (Meldolesi, 2015). Hence, some questions arise: does in the modern advertising era exist a relationship between a naked body and art? When creative advertisers make use of naked bodies, and play with their meaning (eroticism, decency, seduction, sensuality, shame, exhibitionism, and taboos), are they playing also with some form of art?

The present study aims to answer these questions, thus making a new contribution in the area of sexual appeal. Prior research has yielded inconsistent findings indicating both positive and negative effects of sexual appeal on consumer behaviour. Furthermore, attention has been devoted to investigating the effectiveness of explicit sexual stimuli vs non-sexualized advertising. What is unknown is an understanding of the influence of different modes of sexual images representation in advertising. Answering the call for research by Yan, Ogle and Hyllegard (2010), who pointed out the need to further investigate different levels of sexual-stimuli intensity in advertising, the study empirically tests a theoretical framework of the influence that the images of naked bodies, in artistic poses (namely inspired to an artistic work) or provocative poses (just intending to arouse sexual desire or interest), have on consumer responses. Furthermore, concepts related to consumers' emotions, their attitudes towards both the brand and advertising and intent to purchase are taken into consideration.

The paper has also practical implications in relation to advertising strategies and research. From that point of view, a major contribution emerges to improving the communication effectiveness of products and brands that exploit sexual stimuli.

The remainder of the article is organized as follows. The next section reviews the relevant literature and proposes the research hypotheses, while the 'Method' section presents the research design, material used as a stimulus, mode of data collection, and methodology for data analysis. The subsequent sections present the numerical results and discussion, highlighting theoretical and managerial implications. Limits of the study and recommendations for further developments are discussed in the final section.

\section{Theoretical Framework}

\subsection{Use of Sexuality in Advertising}

The World Health Organization's (WHO's) defined sexuality as: "A central aspect of being human throughout life and encompasses sex, gender identities and roles, sexual orientation, eroticism, pleasure, intimacy and reproduction" (2006). Sexuality is, therefore, a broad concept that includes social, emotional, and physical components. It is an element of being human that cannot be separated from other aspects of life: it influences thoughts, feelings, actions and interactions, thus affecting mental and physical health (Langfeldt \& Porter, 1986). For this reason sexuality is often recalled in everyday life situations, including art, cinema, music video, and advertising.

The increasing use of sexual stimuli in advertising might lead one to believe that the saying 'sex sells' is somewhat reliable. The studies on the role of sex in advertising show that this is not always true. Some lines of research, for example, show that the use of sexual stimuli in advertising causes negative consumer feedback (Gould, 1994; LaTour \& Henthorne, 1994) because it shifts their attention from brand names to different arguments related to concern (Blair, Stephenson, Hill, \& Green, 2006), fear, decency or, more generally, immorality (Pollay, 1986). In other research, on the contrary, the use of sexual stimuli, leveraging more instinctive reactions of consumers, produces better outcomes than neutral situations where the subject of sexuality does not appear (Dahl, Sengupta \& Vohs, 2009; Severn, Belch, \& Belch, 1990).

Two research approaches underlie these results: the information processing approach, on the one hand, and the analysis of the hierarchy of the effects, on the other. 
The relevant issues in the first approach deal with the assumption that consumers process stimuli of the advertising through a series of basic cognitive processes. The processes concern, in particular, the ways in which the attention is focused on important elements of the message: if it originates vivid memories, if it improves the recognisability of some immaterial items (brand), and if it creates awareness. In general, the research hypothesis deals with the ways in which sexual content can alter these cognitive processes by reducing or amplifying the effectiveness of the content message and, in particular, the level of persuasion the consumer feels (Reichert, 2002; Thiyagarajan, Shanthi \& Naresh, 2012). The main risk is that the sexual content in advertising, while capturing the consumer's attention, can distract him from other information that is more substantial and relevant as, for example, those related to the brand (MacInnis, Moorman \& Jaworski, 1991; Cui \& Yang, 2009).

Doubtless the use of sexual content in advertising raises the level of attention (Belch, Holgerson, Belch \& Koppman, 1981; Dudley, 1999; Reichert, Heckler \& Jackson, 2001; Reichert, LaTour \& Kim, 2007; Lombardot, 2007) and may help to make those messages more interesting and engaging. A few years ago, Bello, Pitts, and Etzel (1983) manipulated a famous Calvin Klein jeans commercial, in which a seductive Brooke Shields was portrayed, in order to show both the sexy version (original) and the non-sexy version of the ad. The sexy version was considered to be significantly more interesting than the corresponding non-sexy version. Other research measured the ability of consumer to remember and/or recognize different details of the advertisement and highlighted that the attention were significantly captured by contents with a sexual feature (Reid \& Soley, 1983; Reichert \& Alvaro, 2001). However, some studies showed how the presence of sex-related images reduces the ability to encode and remember brand-related information, confirming the existence of a 'distraction effect' (Grazer \& Keesling, 1995). Moreover, the extent of the distraction is likely related to the way the sexual content is bound both to the promoted product and to the text adopted. If sexual information is pointless, that is without an intuitive link with product's properties and text, it is very likely that the distraction effect is pronounced (Severn, Belch \& Belch, 1990).

In summary, the studies conducted in this stream of literature converge on coherent findings: sexual content a) promotes specific attention to the advertisement and improves the memory of allusive images; b) can act as an inhibitor of product/brand coding as it causes the viewer to make use of thoughts and, more generally, of cognitive activities that deal with sexual meanings rather than with the meanings driven by the textual message or by the product/brand (Reichert, 2002).

In the approach that emphasizes the hierarchical analysis of the effects, the relevant issues are the emotions, the attitudes towards both the advertisement and the brand, and the purchase intention.

In this perspective, the attitude is considered as an individual's psychological tendency. It is an evaluation process that assigns positive or negative values to a specific entity (Eagly \& Chaiken, 1993) that can be represented; for example, by an object, an organization or a brand. This implies, necessarily, that the attitude is one evaluative state that stands between the stimulus received by the subject and the answer he gives to that stimulus (Ajzen, 2001; Fishbien \& Ajzen, 1972). Hence, scholars generally agree that consumer attitudes are critical in understanding consumer behaviour and advertising effectiveness. The attitude is powered by affect, namely a set of emotional states, feelings and emotions, of varying intensity. The affect is a triggering condition, a threshold of excitement, which is connected to the entity, or to the stimulus, that generated it (Plutchik, 1980). If affect reaches a certain level of intensity, it is registered as an emotional track, whose characteristic is to be not transient. This gives it the ability to be recalled in future moments reproducing the feelings already tested in the past by the subject. It is just this emotional response, almost automatic, to primarily affect the attitude of the consumer.

In the line of research on the role of sex in advertising, images are accountable to evoke an emotional state that shall be important in the creation of an attitude towards both the advertisement and the advertised brand. Mitchell and Olson (1981) defined attitude towards the brand as an 'individual's internal evaluation of the brand', while attitude towards the advertisement can be considered as an affective evaluation of the overall advertising stimulus that should be treated distinct from beliefs and brand attitudes (Gardner, 1983; Mitchell \& Olson, 1981; Reichert, 2002).

La Tour (1990) demonstrated that when people create positive emotions from images with sexual content included in an advertisement, they tend also to create a positive attitude towards the advertisement. Conversely, if the emotional reaction is negative, then attitude towards the advertisement is negative as well.

Several studies introduced the notion that the attitude of individuals towards the advertisement has a direct effect on purchase intention. As individuals view ads on television, in magazines, or through new media, they form favourable or unfavourable feelings towards the ad that can influence purchase intention (Muehling \& McCann, 
1993). More specifically, positive attitude towards the advertisement tends to produce a stronger motivation to buy the advertised product (e.g. Darley \& Lim, 1981; Mitchell \& Olson, 1981; Gelb \& Pickett, 1983; Cox \& Locander, 1987; Severn et al., 1990). Contextually, some scholars found evidence to support that the intention of consumers to buy a product is likely to be influenced by attitude towards the brand (Laroche \& Brisoux, 1989; Laroche, Kim \& Zhou, 1996). The effect of attitude towards the advertisement and attitude towards brand on purchase intention was also demonstrated in the field of sexual appeal advertising. Wyllie, Carlson, and Rosenberger (2014) suggested that better attitudes towards (a) the advertisement and (b) the brand lead to a higher intention to buy the advertised product.

\subsection{Type of Sexual Content in Advertising}

Empirical research investigated the impact on consumer behaviour of different intensity levels of sexual stimuli in print advertising (Dudley, 1999; Grazer \& Keesling, 1995; LaTour \& Henthorne, 1993, 1994; Severn et al., 1990; Wyllie et al., 2014; Wyllie, Carlson, \& Rosenberger, 2015). The intensity of the stimulus, sexually strong or moderate, was studied by manipulating the level of nudity presented through images. La Tour and Henthorne (1993) demonstrated that university students have a better attitude towards the advertisement when they look at strong sexual images compared to situations in which images have little or no sexual content. Similarly, Grazer and Keesling (1995) and Severn et al., (1990) highlighted that the use of sexually explicit appeals can result in more favourable attitudes which may increase purchase intention for adult respondents. However, other scholars found better attitude towards the advertisement, attitude towards the brand and better purchase intentions for images characterized by a moderate sexual connotation than images with a strong sexual content (LaTour \& Henthorne, 1994; Wyllie et al., 2015). Finally, Wyllie et al., (2014) investigated whether the intensity of the sexual stimuli (mild vs explicit) moderate the paths of relationships among emotions, attitudes towards both the advertisement and the brand, and intention to buy. Their findings suggested that the use of mild sexual stimuli in advertising generates a positive and stronger influence on the relationships shared among affect, attitudes, and purchase intention than do the use of explicit sexual stimuli. These mixed results seem to stem from a gender-difference effect towards sexual-stimuli intensity (e.g. Amyx \& Amyx, 2011; Dahl et al., 2009; Liu, Li \& Cheng, 2006; Sengupta \& Dahl, 2008; Wyllie et al., 2014, 2015). Female consumers hold a higher dislike towards the use of explicit sexual stimuli. Thus, their attitude towards the advertisement, attitude towards the brand and purchase intention increased as the intensity of the sexual stimuli in the advertisement became milder. Conversely, male consumers reported positive reactions and a favourable preference for advertisements depicting explicit sexual stimuli.

The present study intends to contribute to the knowledge on this vein of research by shifting the focus from the intensity of sexual stimuli to the mode of presenting sexual images in advertising. Explicit sexual stimuli can be conveyed through different expressive styles ranging from provocative nudity to artistic styles (i.e. a nude represented according to an artistic work). There are many examples in which advertising recalls some form of art. Advertisers use it both as an integral part of the advertising image and an inspirational model. For example, the statue of David by Michelangelo was coated with Levi's jeans, in the first case, and inspired AX Armani Exchange advertisement in which a half-naked boy is laying in the same position, in the second case. Other examples of these 'insertions or inspirations' are often drawn by masterpieces that are recognized worldwide. The Birth of Venus (Botticelli, 1482-1485) inspired the ad of Indecence perfume by Givenchy; the image of Zeus kidnapping Europe in a bas-relief of the Temple of Selinunte (VI Sec. BC) was used in the corporate advertising of BMW; an advertising campaign of KOOKAI (France, 2001) mimed La Pietà by Michelangelo Buonarroti (1499). There are more recent examples inspired by the painter Klimt or by photographs of iconic significance by Charls Ebbets (1932), such as the Lunch at the Top of the Skyscraper, which has been used by Levi's in 2007 as a driving concept to depict a boy and a girl, both shirtless, lying together on a beam suspended over the city.

With this background, the present work is based on a theoretical framework in which the focus is on the influence on consumer behaviour of nude images, either in poses referring to artistic works or just provocative poses. Although they are both images of naked bodies, sexuality and emotions they evoke may differ. While provocative poses are usually intended to arouse sexual desire or interest, the artistic ones are not expected to give way to arousal or excitement. When people go to art museums they expect to see naked body. Therefore, in the art frame the nude is understood, accepted, and legitimate (Eck, 2001). In light of this evidence, a moderation role of the type of nudity (artistic vs provocative) on the emotions-attitudes-purchase intention relationships is hypothesized. Female consumers show favourable preferences for the use of intimacy and romance in popular culture and mass media communication (Amyx \& Amyx, 2011) and unfavourable attitudes towards sexual images in advertising if perceived as offensiveness (LaTour \& Henthorne, 1994). Therefore, it is likely that they have stronger positive relationships between emotions, attitude towards the advertisement, attitude towards the 
brand, and purchase intention when they are exposed to artistic sexual stimuli compared to provocative sexual stimuli. Conversely, men have different perceptions about what is sexually attractive or being sexy that lead them to have a favourable outlook towards the depiction and use of sexual stimuli in popular culture and mass media communication (Wyllie et al., 2014). Thus, it is expected that males exposed to provocative sexual stimuli show stronger positive relationships between emotions, attitude towards the advertisement, attitude towards the brand, and purchase intention than males exposed to artistic sexual stimuli. More formally, the following hypotheses are formulated:

H1 - Female consumers exposed to artistic sexual stimuli in advertising produce stronger positive relationships between emotions towards the advertisement and (a) attitude towards the advertisement, (b) attitude towards the brand and (c) purchase intention than female consumers exposed to provocative sexual stimuli.

H2 - Female consumers exposed to artistic sexual stimuli in advertising produce stronger positive relationships between attitude towards the advertisement and purchase intention than female consumers exposed to provocative sexual stimuli.

H3 - Female consumers exposed to artistic sexual stimuli in advertising produce stronger positive relationships between attitude towards the brand and purchase intention than female consumers exposed to provocative sexual stimuli.

H4 - Male consumers exposed to provocative sexual stimuli in advertising produce stronger positive relationships between emotions towards the advertisement and (a) attitude towards the advertisement, (b) attitude towards the brand and (c) purchase intention than male consumers exposed to artistic sexual stimuli.

H5 - Male consumers exposed to provocative sexual stimuli in advertising produce stronger positive relationships between attitude towards the advertisement and purchase intention than male consumers exposed to artistic sexual stimuli.

H6 - Male consumers exposed to provocative sexual stimuli in advertising produce stronger positive relationships between attitude towards the brand and purchase intention than male consumers exposed to artistic sexual stimuli.

Figure 1 provides the conceptual model based on the aforementioned hypotheses.

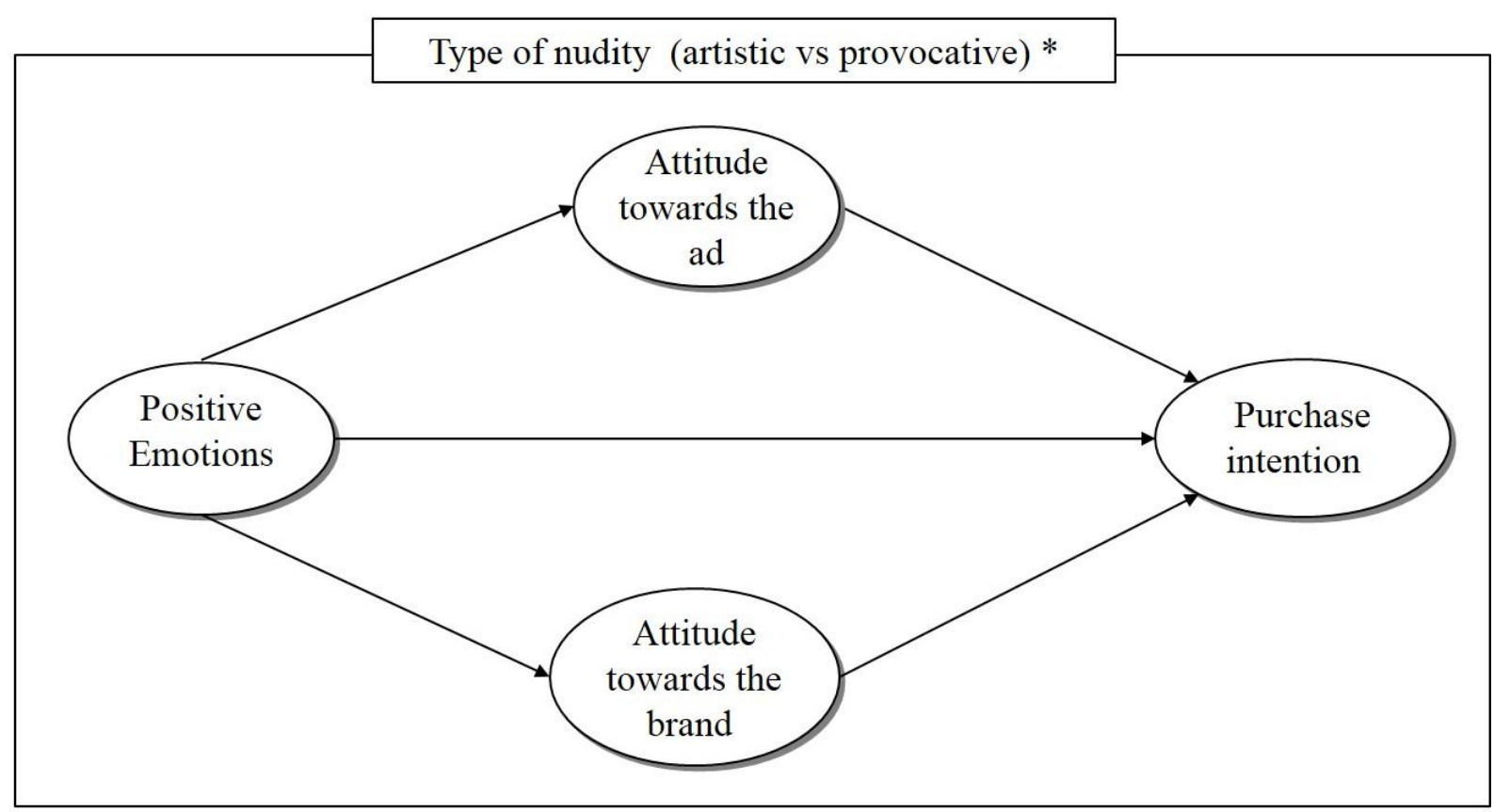

* moderating variable

Figure 1. Theoretical framework of the study 


\section{Method}

\subsection{Measures}

The items used to measure the latent constructs were drawn from scales that have been well validated in the literature. The measure for attitude towards the advertisement (Att_ad) was adopted from the five-item scale developed by Lee and Mason (1999). Statements were on a 7-point Likert scale $(1=$ completely disagree; $7=$ completely agree). Areliability analysis carried out on these five items showed a Cronbach's alpha of 0.86 .

Attitude towards the brand (Att_brand) was measured using a five-item bipolar scale (ranging from 1 to 7 ) derived from Putrevu (2008). Cronbach's alpha indicated that the scale was internally consistent $(\alpha=0.78)$.

Ten items from the PANAS scale (Watson, Clark, \& Tellegen, 1988) was used to assess positive emotions (PE). Statements were on a 5 -point scale (from $1=$ not at all, to $5=$ extremely). Cronbach's alpha showed good levels of internal consistency of the scale $(\alpha=0.90)$.

Questions measuring purchase intention (PI) were adaptations of the 3 -item scale proposed by Putrevu (2008). Responses ranged from 1 (= unlikely) to 7 (= likely). Cronbach's alpha indicated that the scale was internally consistent $(\alpha=0.83)$.

All items used in the questionnaire are showed in Appendix A with the relative reliability indexes.

\subsection{Advertisement Stimuli}

Two colourful print ads were created as stimuli for the study. The selection of the two images involved a pre-test of ten images of naked bodies, five recalling some form of art (artistic nudity), and five just intending to arouse sexual desire or interest (provocative nudity). Two groups of twenty students each evaluated, on a seven-point scale, the five artistic images (from "not artistic" to "very artistic") and the five provocative images (from "not provocative" to "very provocative"), respectively. The two artistic and provocative images with the higher rating were used for creating the ads stimuli. The first one (Figure 2), featuring an artistic nudity, contained a nude female model sitting and hugging her legs (AN). The advertising image adopted in the ad is deeply inspired by Jean-Hippolyte Flandrin's painting, 'Young Man sitting beside the Sea' (1836; Louvre Museum). It is not the first time that this famous painting has been imitated by advertisers. A man portrayed in the same posture of the Flandrin's painting has been adopted as the image of an Institutional campaign by the Italian Government to promote accurate information on AIDS (1987), in the campaign by Diadora (1991) and in a famous campaign of Yves Saint Laurent (1998). In the last case, the postures of the model, Kate Moss, mimic a large number of artworks, including that of Flandrin. The second ad (Figure 3), featuring provocative nudity, contained a nude female model lying on the water (PN). The image is taken from a famous shot of the British actress and model Cara Delevingne. She appears like a nymph; her body is half immersed in a pool of dark water where several orchids float. The nude is elegant but explicit, so that her B side is fully visible. The image has an ethereal allure, but at the same time is extremely sexy.

The sponsored product chosen was a well-known branded perfume which is available in male and female fragrances (Aqua di Giò by Armani). Both ads were manipulated to represent, alternately, the male and female version of the product. Therefore, four images were created: the ad featuring the artistic nudity and showing the female's fragrance perfume; the ad featuring the artistic nudity and showing the male's fragrance perfume; the ad featuring the provocative nudity and showing the female's fragrance perfume; the ad featuring the provocative nudity and showing the male's fragrance perfume.

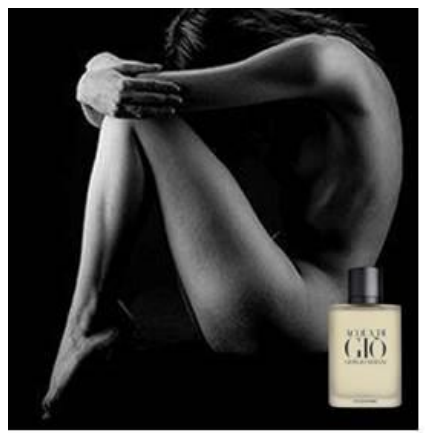

Image in the ad (AN) male fragrance

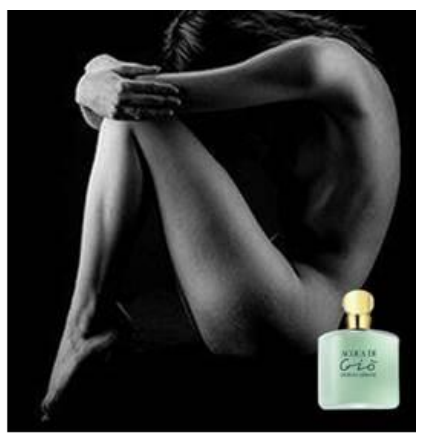

Image in the ad (AN) female fragrance

Figure 2. Artistic nudity stimulus 


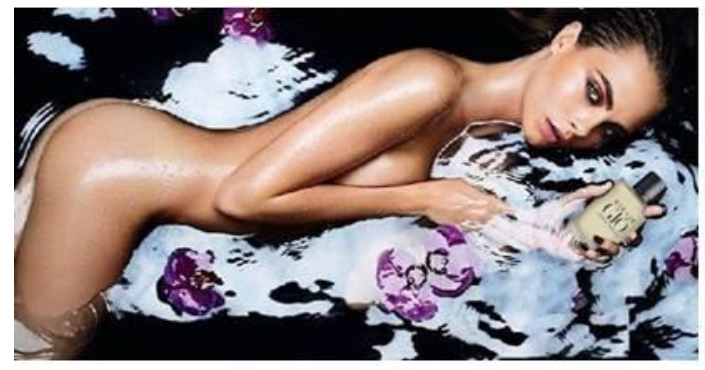

Image in the ad (PN) male fragrance



Image in the ad (PN) female fragrance

Figure 3. Provocative nudity stimulus

\subsection{Sample and Procedure}

A between-subjects experimental design was conducted. A self-administered questionnaire was sent in electronic form to a sample of 5000 undergraduate students from a University in northern Italy, of which 2500 male and 2500 female. Males received a questionnaire containing the image of the male's fragrance perfume, while women were exposed to the ad of the female's fragrance perfume. Half of the males received the artistic nudity ad and the other half the provocative nudity ad. The same happened for the female sample. The distribution of subjects between the two conditions (artistic vs provocative) was random.

The use of a student sample is supported for theory-application research because of the homogeneous nature of students in regards to both their demographic and behavioural characteristics (Calder, Phillips \& Tybout, 1981; Carpenter, Moore \& Fairhurst, 2005). Moreover, the selected product is expressly targeted for youth.

Out of 387 completed questionnaires, 18 were then excluded as they did not provide complete data, thus reducing the number of usable responses to 369 (51\% men and 49\% women, with a mean age of 25,34). Among them, 164 (50\% men and 50\% women) evaluated the provocative nudity ad and 205 (52\% men and 48\% women) the artistic nudity ad.

\subsection{Analytical Procedure}

Data underwent three phases of analysis. First, an examination of the measurement model, which is equivalent to a confirmatory factor analysis (CFA) with the latent variables considered, was performed to obtain evidence of convergent and discriminant validity of the measurement scales. Second, the paths of relationships between the latent variables were explored and configural, metric and scalar invariance models were estimated to identify the baseline model against which the theoretical model can be compared. In the third analysis phase, the hypothesized moderating effects were estimated.

Structural equation modelling (SEM) with maximum likelihood method was employed for the analysis of the measurement and conceptual models. The data were analysed in Lisre1 8.80.

The fit of the models was interpreted based on a range of fit indices, namely the Chi-square $\left(\chi^{2}\right)$ value, the degree of freedom (df), the comparative fit index (CFI), the non-normed fit index (NNFI) and the root mean square error of approximation (RMSEA). A good fit of the data was indicated by a chi-square/degrees of freedom value less than 4 (Field, 2000). Values in the 0.90 range and above have been deemed acceptable for CFI and NNFI (Hooper, Coughlan \& Mullen, 2008; Hu \& Bentler, 1995). Values lower than 0.10 have been deemed acceptable for the RMSEA (Bollen, 1989; Browne \& Cudeck, 1993).

\section{Results}

\subsection{Measurement Model}

To check convergent and discriminant validity of the measurement scales, two confirmatory factor analysis were estimated; one for the female sample and one for the male sample combining the artistic nudity ad and the provocative nudity ad.

As the skew and kurtosis statistics showed that the normality assumption was violated, the models were estimated using the Satorra-Bentler method (Satorra \& Bentler, 1994).

The fit statistics indicated that the measurement models fit the data well for both groups (male sample: $\chi^{2}=$ $374.31, \mathrm{df}=203, p=0.000, \mathrm{CFI}=0.96, \mathrm{RMSEA}=0.07, \mathrm{NNFI}=0.96$; female sample: $\chi^{2}=448.16, \mathrm{df}=203, p=$ $0.00, \mathrm{CFI}=0.96, \mathrm{RMSEA}=0.08, \mathrm{NNFI}=0.95)$. 
Convergent validity was tested by checking that all items substantially and significantly loaded onto the expected latent construct (Anderson \& Gerbing, 1988). Factor loadings ranged from 0.38 to 0.93 , with the lowest $t$-value being 3.68. Moreover, all constructs showed satisfactory levels of Composite Reliability (CR) and Average Variance Extracted (AVE). Next, discriminant validity was assessed by the Fornell and Larcker's (1981) criterion. The average variance explained by each latent variable was greater than any of the squared correlations involving the variable, suggesting that discriminant validity was achieved. Collectively, these results show that the measures are unidimensional, reliable, and exhibit convergent and discriminant validity for both samples.

Table 1 reports the convergent and discriminant validity indexes of each construct.

Table 1. CFA: factor loadings, CR and AVE of latent variables

\begin{tabular}{llcccc}
\hline & \multicolumn{2}{c}{ Males } & & \multicolumn{2}{c}{ Females } \\
\cline { 2 - 6 } \cline { 4 - 6 } & CR & AVE & CR & AVE \\
\hline Positive Emotions & 0.91 & 0.50 & 0.90 & 0.49 \\
Attitude towards the advertisement & 0.84 & 0.52 & 0.88 & 0.59 \\
Attitude towards the brand & 0.76 & 0.62 & 0.80 & 0.50 \\
Purchase intention & 0.82 & 0.87 & 0.70 \\
\hline
\end{tabular}

\subsection{Tests of the Conceptual Model}

To test the overall validity of the conceptual framework, two structural models were estimated, one for the female sample and one for the male sample. For each group, the paths of relationships between the latent variables were investigated by using the total sample data (combining the artistic nudity ad and the provocative nudity ad).

The results indicated that the model fits the data well for both groups (male sample: $\chi^{2}=403.27, \mathrm{df}=204, p=$ $0.000, \mathrm{CFI}=0.96, \mathrm{RMSEA}=0.07, \mathrm{NNFI}=0.96$; female sample: $\chi^{2}=492.79, \mathrm{df}=204, p=0.00, \mathrm{CFI}=0.95$, RMSEA $=0.09, \mathrm{NNFI}=0.95$ ). Overall, the model explains $39 \%$ of the variance for purchase intention in the male sample and $52 \%$ in the female sample.

The examination of the path coefficients and t-values indicated that positive emotions towards the advertisement exerts significant positive influences on attitude towards the advertisement $\left(\gamma_{\text {men }}=0.656, p<0.01 ; \gamma_{\text {women }}=\right.$ $0.673, p<0.01)$ and attitude towards the brand $\left(\gamma_{\operatorname{men}}=0.335, p<0.01 ; \gamma_{\text {women }}=0.303, p<0.01\right)$ for both men and women. By contrast, positive emotions did not emerge as a relevant predictor of purchase intention. Consistent with literature results (Laroche \& Brisoux, 1989; Laroche, Kim \& Zhou, 1996; Willie, Carlson and Rosenberger 2014), a better attitude towards the brand resulted in an increase of purchase intention for both men and women $\left(\beta_{\mathrm{men}}=0.591, p<0.01 ; \beta_{\mathrm{women}}=0.497, p<0.01\right)$. Finally, a more favourable attitude towards the advertisement increases the purchase intention of females $\left(\beta_{\text {women }}=0.364, p<0.01\right)$. Despite showing the same positive sign, the parameter did not approach significance for the male sample.

\subsection{Hypotheses Testing}

To investigate the potential moderating role of the type of nudity, the model was tested simultaneously on the artistic nudity ad group and the provocative nudity ad group. Two separate analyses were carried out for males and for females.

As configural and metric invariance was supported for both gender samples, the relevant structural parameters were constrained to be equal across groups to test each moderator hypothesis. Scalar invariance was not supported for the male sample, as the $\chi^{2}$ difference test indicated a significant deterioration in the fit of the constrained model. Therefore, comparisons between the means of the latent variables were not performed. Results are described separately for male and female samples.

In the female sample, the model fits the two-group data well $\left(\chi^{2}=943.99, \mathrm{df}=445, p=0.00, \mathrm{CFI}=0.95\right.$, RMSEA $=0.08$, NNFI $=0.95)$. These results served as the benchmark for testing each of the moderator hypotheses (Hair, Black, Babin, Anderson \& Tatham, 2006).

The moderation analysis provided support for the hypothesis $\mathrm{H} 2$. The $\chi^{2}$ difference test between the constrained model and the benchmark model was significant $\left(\Delta \chi_{(1)}^{2}=5.54, \mathrm{p}<0.05\right)$ and results showed that attitude towards the advertisement exerted significantly stronger positive influence on the purchase intention for women watching artistic nudity advertisement compared to women watching provocative nudity advertisement $(\beta=$ $1.230, p<0.01$ vs $\beta=0.092, p>0.05$ ). By contrast, the positive effect of attitude towards the brand on purchase intention was significantly weaker for women watching artistic nudity advertisement $(\beta=0.517, p<0.05$ vs $\beta=$ $1.147, p>0.01$ ). Therefore, $\mathrm{H} 3$ was not supported as the relationship found was reversed compared with the expectations. Finally, no moderating effect of type of nudity was found in the relationship between positive emotions and the other latent variables. Hence, $\mathrm{H} 1$ was not supported by the data. 
In the male sample, the model displayed good global level of fit $\left(\chi^{2}=800.31, \mathrm{df}=445, p=0.00, \mathrm{CFI}=0.96\right.$, RMSEA $=0.07, \mathrm{NNFI}=0.95$ ).

A moderating effect of type of nudity was found in the positive emotion-to-attitude towards the brand path. Indeed, the $\chi^{2}$ difference test between the constrained model and the benchmark model was significant $\left(\Delta \chi_{(1)}^{2}=\right.$ $5.35, \mathrm{p}<0.05$ ). However, results did not support H4b as the relationship found was reversed compared with the expectations: positive emotions exerted significantly stronger positive influence on attitude towards the brand for subjects watching artistic nudity advertisement compared to subjects watching provocative nudity advertisement $(\gamma=0.827, p<0.01$ vs $\gamma=0.228, p>0.05)$. No support for the moderating effect of type of nudity in the other relationships hypothesized in $\mathrm{H} 4 \mathrm{a}, \mathrm{H} 4 \mathrm{c}, \mathrm{H} 5$ and $\mathrm{H} 6$ was found. The relationships between (a) PE and Att_ad, (b) PE and PI, (c) Att_ad and PI and (d) Att_brand and PI did not differ between male consumers exposed to provocative sexual stimuli and male consumers exposed to artistic sexual stimuli.

The structural coefficients for the artistic nudity ad group and the provocative nudity ad group are reported in Table 2.

Table 2. Structural coefficients for the artistic nudity ad group and the provocative nudity ad group

\begin{tabular}{|c|c|c|c|c|}
\hline & \multicolumn{2}{|c|}{ Males } & \multicolumn{2}{|c|}{ Females } \\
\hline & Artistic & Provocative & Artistic & Provocative \\
\hline PE $\rightarrow$ Att_brand & $0.827 * *$ & 0.228 & $0.593 * *$ & 0.238 \\
\hline PE $\rightarrow$ Att_ad & $0.727 * *$ & $0.827 * *$ & $0.755^{* *}$ & $0.897 * *$ \\
\hline $\mathrm{PE} \rightarrow \mathrm{PI}$ & 0.436 & -0.356 & 0.086 & 0.492 \\
\hline Att_brand-> PI & $1.107 * *$ & $0.669 * *$ & $0.517 *$ & $1.147 * *$ \\
\hline Att_ad-> PI & -0.162 & 0.399 & $1.23 * *$ & 0.092 \\
\hline
\end{tabular}

\section{Discussion}

Previous empirical research on different intensity levels of sexual appeals in advertising has yielded both positive and negative effects on consumer behaviour. These mixed results seem to stem from a gender-difference effect: compared to male consumers, female hold a higher dislike and a less favourable affective, attitudinal and behavioural responses towards the use of explicit sexual stimuli (e.g. Amyx \& Amyx, 2011; Dahl et al., 2009; Liu et al., 2006; Sengupta \& Dahl, 2008; Wyllie et al., 2014, 2015). The present study extends prior research on explicit sexual stimuli in print advertising by examining the mode of representing sexual images. Specifically, the focus is on the influence of nudes images in poses mentioning artistic works or in just provocative poses on the behaviour of male and female consumers. In a context where advertising literature recommends extreme caution when using explicit sexual appeals, exploring different expressive styles can help the effective design and selection of such stimuli.

In general, the findings show that although the mode of representing sexual images did not exert a significant effect on all the relationships shared amongst emotions, attitudes, and purchase intention, the use of images in poses mentioning artistic works generated more favourable responses than did the use of images in just provocative poses.

From a female consumer perspective, all paths are positive and significant when exposed to the artistic nudity stimuli, with the only exception of the positive emotions-purchase intention relationship. On the contrary, the influence on the system of relationships decreases with the use of provocative images. Only positive emotions and attitude towards the brand exert a positive and significant impact: the former on attitude towards the advertisement, and the latter on purchase intention. Furthermore, the findings suggest a moderating role of the mode of representing sexual images on attitude-intention relationships. On one hand, attitude towards the advertisement generated significantly stronger positive influence on purchase intention for women watching artistic nudity advertisement; on the other hand, attitude towards the brand produced significantly stronger positive effect on purchase intention for women watching provocative nudity advertisement.

The results of the present study shed new light into the responses that female consumers have towards explicit sexual appeals. To date, it was acknowledged that women tend to react more favourably when exposed to non-sexualized stimuli or mild sexual stimuli compared to explicit sexual appeals (e.g. LaTour \& Henthorne, 1994; Wyllie et al., 2014). Conversely, explicit sexual stimuli are also effective towards a female target provided that nudity mentions artistic works. Therefore, concerns associated with this type of advertising strategy disappear and new opportunities emerge.

An unexpected finding of the present study is that the relationship between attitude towards the brand and purchase intention is significantly stronger when women are exposed to a provocative sexual image compared to 
an artistic one. Further research is needed to validate this effect that would offer the possibility to use provocative nudity in reinforcing the brand attitude-purchase intention link for female consumers.

From a male consumer perspective, the response towards sexual appeals was similar to that of female. One notable exception occurred where any effect was present between attitude towards the advertisement and purchase intention. This result is contrary to the findings in the literature (Amyx \& Amyx, 2011; LaTour \& Henthorne, 1994; Sengupta \& Dhal, 2008), but in line with the study by Wyllie et al. (2014). Although the authors found a positive influence of explicit sexual stimuli on the emotional and attitudinal responses of male consumer, this does not necessarily translate into the intent to purchase.

A moderating effect emerged in positive emotion-to-attitude towards the brand path. Specifically, positive emotions exerted an influence towards the brand for male watching artistic nudity advertisement. Therefore, it may be suggested that either an artistic nudity image or a provocative nudity one can be successfully used to positively influence a male audience. Nevertheless the artistic sexual stimuli give the advantage to reinforce the relationship between positive emotions and brand attitude.

Overall, it may be said that nude images in poses mentioning artistic work provide the opportunity to design effective explicit sexual appeal advertising strategy to positively influence attitude and purchase intention of both female and male consumers.

\section{Limitations and Future Research}

Some limitations related to the current study should be acknowledged.

Even if the results of the study shed new lights on the way explicit sexual stimuli can be represented (artistic versus provocative), it is focused on a female model alone. Further research should investigate both the role of male model alone and even the role of a couple in artistic or provocative poses.

Photos used in the study are coloured, in provocative condition, and black and white in the artistic one. The artistic condition is undoubtedly due to the pose of female model that recall the famous picture of Flandrin; nonetheless, the black and white option emphasizes the artistic content if compared with a coloured one. So it is possible that the black and white photo increases the artistic effect of the model pose.

The sample composition of the study has focussed on the student target, since the brand product has a market positioning right in that segment; further studies should include male and female respondents of different ages.

These arguments may have partially influenced the findings of the study, limiting its generalizability. Even with this limitation from the sampling method adopted, the findings can be still considered relevant, given the theory-building purposes of this study, which is focused on the role of artistic versus provocative sexual stimuli on purchase intention.

Finally, further research in this field should investigate the role of cultural context in consumer responses.

In conclusion, this study has advanced our understanding of the influence of expressive styles in explicit se xual appeal advertising. The use of an artistic format will stimulate a better response, both on male and female, than the use of images in merely provocative poses.

\section{References}

Ajzen, I. (2001). Nature and operation of attitudes, Annual Review of Psychology, 52, 27-58. https://doi.org/10.1146/annurev.psych.52.1.27

Amyx, D., \& Amyx, K. (2011). Sex and puffery in advertising: An absolutely sensational and sexually provocative experiment. International Business and Management, 2(1), 1-10.

Anderson, J. C., \& Gerbing D. W. (1988). Structural Equation Modeling in practice: Areview and recommended two-step approach. Psychological Bulletin, 103(3), 411-423. https://doi.org/10.1037/0033-2909.103.3.411

Belch, M. A., Holgerson, B. E, Belch, G. E., \& Koppman, J. (1981). Psychophysical and cognitive responses to sex in advertising. Advances in consumer research, 9, 424-427.

Bello, D. C., Pitts, P. E., \& Etzel, M. J. (1983). The communication effects of controversial sexual content in television programs and commercials. Journal of Aduertising, 12(3), 32-43. https://doi.org/10.1080/00913367.1983.10672846

Blair, J., Stephenson, Hill, J. K., \& Green, J. (2006). Ethics in advertising: Sex sells, but should it? Journal of Le gal, Ethical and Regulatory Issues, 9(2), 109-118.

Bollen, K. A. (1989). Structural Equations with Latent Variables. New York, NY : Wiley Interscience. 
https://doi.org/10.1002/9781118619179

Browne, M. W., \& Cudeck, R. (1993). Alternative ways of assessing model fit. Sage Focus Editions, 154, 136-136.

Calder, B. J., Phillips, L., \& Tybout, A. (1981). Designing research for application, Journal of Consumer Research, 8(2), 197-207. https://doi.org/10.1086/208856

Carpenter, J., Moore, M., \& Fairhurst, A. (2005). Consumer shopping value for retail brands. Journal of Fashion Marketing and Management, 9(1), 43-55. https://doi.org/10.1108/13612020510586398

Cox, D. S., \& Locander, W. B. (1987). Product novelty: does it moderate the relationship between ad attitudes and brand attitudes? Journal of Advertising, 16(3),39-44. https://doi.org/10.1080/00913367.1987.10673084

Cui, G., \& Yang X. (2009). Responses of Chinese consumers to sex appeals in international advertising: Atest of congruency theory, Journal of Global Marketing, 22(3), 229-245. https://doi.org/10.1080/08911760902845031

Dahl, D., Sengupta J., \& Vohs, K. (2009). Sex in advertising: Gender differences and the role of relationship commitment. Journal of Consumer Research, 36(2), 1-31. https://doi.org/10.1086/597158

Darley, W. K., \& Lim, J. S. (1991). Personal relevance as moderator of the effect of public service advertising on behaviour. Advances in consumer research, 18(1), 303-309.

Dudley, S. (1999). Consumer attitude towards nudity in advertising. Journal of Marketing Theory and Practice, 7(4), 89-96. https://doi.org/10.1080/10696679.1999.11501854

Eagly, A. H., \& Chaiken, S. (1993). The psychology of attitudes. Harcourt Brace College Publishers.

Eck, B. A. (2001). Nudity and framing: Classifying art, pornography, information, and ambiguity. Sociological Forum, 16(4), 603-632. https://doi.org/10.1023/A:1012862311849

Field, A. (2000). Discovering statistics using SPSS for windows. London: Sage.

Fishbien, M., \& Ajzen, I. (1972). Attitudes and opinions. Annual Review of Psychology, 23, 487-544. https://doi.org/10.1146/annurev.ps.23.020172.002415

Fornell, C., \& Larcker, D. F., (1981). Structural equation models with unobservable variables and measurement error: Algebra and statistics. Journal of marketing research, 382-388. https://doi.org/10.2307/3150980

Gardner, M. P. (1983). Advertising effects on attributes recalled and criteria used for brand evaluations. Journal of Consumer Research, 10(3), 310-318. https://doi.org/10.1086/208970

Gelb, B. D., \& Pickett, C. M. (1983). Attitude-toward-the-ad: Links to humor and to advertising effectiveness. Journal of Advertising, 12(2), 34-42. https://doi.org/10.1080/00913367.1983.10672838

Gould, S. J. (1994). Sexuality and ethics in advertising: A research agenda and policy guideline perspective. Journal of Advertising, 23(3), 73-80. https://doi.org/10.1080/00913367.1994.10673452

Grazer, W. R., \& Keesling, G. (1995). The effect of printing advertising's use of sexual themes on brand recall and purchase intention: a product specific investigation of male responses. Journal of Applied Business Research, 11(2), 47-57.

Hair, J. F., Black,W. C., Babin, B. J., Anderson, R. E., \& Tatham, R. L. (2006). Multivariate Data Analysis. Saddle River, NJ: Prentice Hall Upper.

Hooper, D., Coughlan, J., \& Mullen, M. (2008). Structural equation modelling: Guidelines for determining model fit. Electronic Journal of Business Research Methods, 6(1), 53-60.

Howard, V. (2000). At the curve exchange: Postwar beauty culture and working women at maidenform, Enterprise and Society, 1(3), 591-618. https://doi.org/10.1093/es/1.3.591

Hu, L. T., \& Bentler, P. M. (1995). Evaluating model fit. In R. H. Hoyle (Ed.) Structural equation modeling: Concepts, issues, and applications, (pp. 76-99). Thousand Oaks, CA: Sage.

Langfeldt, T., \& Porter, M. (1986). Sexuality and family planning: Report of a consultation and research findings. Copenhagen: World Health Organization, Regional Office for Europe.

Laroche, M., \& Brisoux, J. E., (1989). Incorporating competition into consumer behavior models: The case of the attitude-intention relationship. Journal of Economic Psychology, 10, 343-362.

https://doi.org/10.1016/0167-4870(89)90029-9 
Laroche, M., Kim, C., \& Zhou, L. (1996). Brand familiarity and confidence as determinants of purchase intention: An empirical test in a multiple brand context. Journal of business Research, 37(2), 115-120. https://doi.org/10.1016/0148-2963(96)00056-2

LaTour, M. S. (1990). Female nudity in print advertising: An analysis of gender differences in arousal and ad response. Psychology \& Marketing, 7, 65-81. https://doi.org/10.1002/mar.4220070106

LaTour, M. S., \& Henthorne, T. L. (1993). Female nudity: Attitudes toward the ad and the brand, and implications for advertising strategy. Journal of Consumer Marketing, 10(3), 25-32. https://doi.org/10.1108/07363769310041956

LaTour, M. S., \& Henthorne, T. L. (1994). Ethical judgments of sexual appeals in print advertising. Journal of advertising, 23(3), 81-90. https://doi.org/10.1080/00913367.1994.10673453

Lee, Y. H., \& Mason, C. (1999). Responses to information incongruency in advertising: The role of expectancy, relevancy, and humor. Journal of consumer research, 26(2), 156-169. https://doi.org/10.1086/209557

Liu, F., Li, J., \& Cheng, H. (2006). Sex appeal advertising: gender differences in Chinese consumers' responses. Asia Pacific Journal of Marketing and Logistics, 18(1), 19-28. https://doi.org/10.1108/13555850610641064

Lombardot, E. (2007). Nudity in advertising: what influence on attention-getting and brand recall?. Recherche et Applications en Marketing, 22(4), 23-41. https://doi.org/10.1177/076737010702200401

MacInnis, D. J., Moorman, C., \& Jaworski, B. J. (1991). Enhancing and measuring consumers' motivation, opportunity, and ability to process brand information from ads. Journal of Marketing, 55, 32-53. https://doi.org/10.2307/1251955

Meldolesi, A. (2015). Elogio della nudità. Milano: Bompiani Editore.

Mitchell, A. A., \& Olson, J. C. (1981). Are product attribute beliefs the only mediator of advertising effects on brand attitude?. Journal of Marketing Research, 18, 318-332. https://doi.org/10.2307/3150973

Muehling, D. D., \& McCann, M. (1993). Attitude towards the ad: A review. Journal of Current Issues and Research in Advertising, 15(2), 25-58. https://doi.org/10.1080/10641734.1993.10505002

Plutchik, R. (1980). ALanguage for the emotions. Psychology Today, February, 68-78.

Pollay, R. W. (1986). Quality of life in the padded sell: Common criticisms of advertising's cultural character and international public policies. Current Issues and Research in Advertising, 9(1-2), 173-250.

Putrevu, S. (2008). Consumer responses toward sexual and nonsexual appeals: The influence of involvement, need for cognition (NFC), and gender. Journal of Advertising, 37(2), 57-70. https://doi.org/10.2753/JOA0091-3367370205

Reichert, T. (2002). Sex in advertising research: Areview of content, effects, and functions of sexual information in consumer advertising. Annual review of sex research, 13(1), 241-273.

Reichert, T., \& Alvaro, E. (2001). The effects of sexual information on ad and brand processing and recall, Southwestern mass communication journal, 17(1), 9-17.

Reichert, T., Heckler, S. E., \& Jackson, S. (2001). The effects of sexual social marketing appeals on cognitive processing and persuasion. Journal of Advertising, 30(1), 13-27. https://doi.org/10.1080/00913367.2001.10673628

Reichert, T., LaTour, M. S., \& Kim, J. Y. (2007). Assessing the influence of gender and sexual self-schema on affective responses to sexual content in advertising. Journal of Current Issues and Research in Advertising, 29(2), 63-77. https://doi.org/10.1080/10641734.2007.10505217

Reid, L. N., \& Soley, L. C. (1983). Decorative models and the readership of magazine ads. Journal of Advertising Research, 23(2), 27-32.

Satorra, A., \& Bentler, P. M. (1994). Corrections to test statistics and standard errors in covariance structural analysis. In Von Eye, A., \& Clogg C.C. (Eds). Latent variables analysis: Applications for developmental research (pp. 399-419), Thousand Oaks, CA: Sage.

Sengupta, J., \& Dahl, D., (2008). Gender related reactions to gratuitous sex appeals in advertising. Journal of Consumer Psychology, 18(1), 62-78. https://doi.org/10.1016/j.jcps.2007.10.010

Severn, J., Belch, G. E., \& Belch, M. A. (1990). The effects of sexual and non-sexual advertising appeals and information level on cognitive processing and communication effectiveness. Journal of Advertising, 19(1), 


\section{4-22. https://doi.org/10.1080/00913367.1990.10673176}

Thiyagarajan S., Shanthi, P., \& Naresh, G. (2012). Viewers' perception of tv ads: The role of sex appeal, Psychology Research, 2(8), 452-460. https://doi.org/10.17265/2159-5542/2012.08.002

Watson, D., Clark, L. A., \& Tellegen, A. (1988). Development and validation of brief measures of positive and negative affect: the PANAS scales. Journal of personality and social psychology, 54(6), 1063-1070. https://doi.org/10.1037/0022-3514.54.6.1063

World Health Organization. (2002). Defining sexual health. Report of a technical consultation on sexual health. Retrieved from: http://www.who.int/reproductivehealth/topics/gender_rights/defining_sexual_health.pdf

Wyllie, J., Carlson, J., \& Rosenberger, P. J. III. (2014). Examining the influence of different levels of sexual-stimuli intensity by gender on advertising effectiveness. Journal of Marketing Management, 30(7-8), 697-718. https://doi.org/10.1080/0267257X.2013.838988

Wyllie, J., Carlson, J., \& Rosenberger, P. J. III. (2015). Does sexual-stimuli intensity and sexual self-schema influence female consumers' reactions towards sexualised advertising? An Australian perspective. Australasian Marketing Journal, 23(3), 188-195. https://doi.org/10.1016/j.ausmj.2015.06.004

Yan, R., Ogle, J. P., \& Hyllegard, K. H. (2010). The impact of message appeal and message source on Gen Y consumers' attitudes and purchase intentions toward American Apparel. Journal of Marketing Communications, 16(4), 203-224. https://doi.org/10.1080/13527260902863221

Appendix A. Items of the questionnaire

\begin{tabular}{|c|c|c|}
\hline Construct & Items & $\alpha$ \\
\hline $\begin{array}{l}\text { Positive emotions } \\
\text { (Watson, Clark \& } \\
\text { Tellegen, 1988) }\end{array}$ & $\begin{array}{l}\text { Interested } \\
\text { Excited } \\
\text { Strong } \\
\text { Enthusiastic } \\
\text { Proud } \\
\text { Alert } \\
\text { Inspired } \\
\text { Determined } \\
\text { Attentive } \\
\text { Active }\end{array}$ & 0.90 \\
\hline $\begin{array}{l}\text { Attitude towards the } \\
\text { advertisement } \\
\text { (Lee \& Mason, 1999) }\end{array}$ & $\begin{array}{l}\text { I dislike the ad } \\
\text { The ad is appealing to me } \\
\text { The ad is attractive to me } \\
\text { The ad is interesting to me } \\
\text { I think the ad is bad }\end{array}$ & 0.86 \\
\hline $\begin{array}{l}\text { Attitude towards the } \\
\text { brand } \\
\text { (Putrevu, 2008) }\end{array}$ & $\begin{array}{l}\text { This brand is... } \\
\text { Dislike/Like } \\
\text { Bad/Good } \\
\text { Unfavourable/Favourable } \\
\text { Useless/Useful }\end{array}$ & 0.78 \\
\hline $\begin{array}{l}\text { Purchase intention } \\
\text { (Putrevu, 2008) }\end{array}$ & $\begin{array}{l}\text { How likely is it that you will consider this brand the next time you } \\
\text { purchase fragrance } \\
\text { The next time I consider purchasing fragrance, I will enquire about this } \\
\text { brand } \\
\text { The next time I buy fragrance, I will buy this brand }\end{array}$ & 0.83 \\
\hline
\end{tabular}

\section{Copyrights}

Copyright for this article is retained by the author(s), with first publication rights granted to the journal.

This is an open-access article distributed under the terms and conditions of the Creative Commons Attribution license (http://creativecommons.org/licenses/by/4.0/). 